\section{Commentary: Evidence or anecdote?}

\author{
Vijay S. Patel, MD, and Richard Lee, MD, MBA
}

Atrial fibrillation (AF), the most common arrhythmia, continues to increase in prevalence, with a significant impact on patient morbidity, mortality, and health care costs. ${ }^{1}$ The coexistence of AF and heart failure (HF) portends an even greater deleterious impact on long-term patient outcomes. ${ }^{2}$

It was a pleasure to read the article by Khiabani and colleagues," "Surgical ablation of atrial fibrillation in patients with heart failure," in this issue of the Journal. The article is well organized, with a description of the subset of AF patients with HF composing the tachycardia-induced cardiomyopathy (TIC) population, followed by discussions of the medical and catheter ablation strategies currently deployed for their management and outcomes, patient selection for the biatrial Cox-maze IV procedure (CMP-IV) for SA, and rationale for advancing a stand-alone surgical ablation (SA) strategy for patients diagnosed with TIC refractory to a medical and/or catheter ablation strategy. The authors recommend offering concomitant SA to patients with $\mathrm{AF}$ and $\mathrm{HF}$ diagnosed with correctable structural heart disease; the perioperative and long-term benefits of this strategy have been well described. ${ }^{4,5}$

An important and pivotal clinical practice message is the need to distinguish patients with $\mathrm{HF}$ as a result of $\mathrm{AF}$ (eg, the TIC cohort) from those who develop AF due to irreversible HF. This cannot be overemphasized. The article provides an algorithmic approach for diagnostic and therapeutic management before and after surgical referral. The diagnostic guidance emphasizes the exclusion of patients with irreversible etiology for $\mathrm{HF}$, including dilated cardiomyopathy, cardiac fibrosis, and infiltrative cardiac diseases, and highlights the utility of cardiac magnetic

From the Division of Cardiothoracic Surgery, Department of Surgery, Medical College of Georgia, Augusta University, Augusta, Ga.

Disclosure: The authors reported no conflicts of interest.

The Journal policy requires editors and reviewers to disclose conflicts of interest and to decline handling or reviewing manuscripts for which they may have a conflict of interest. The editors and reviewers of this article have no conflicts of interest

Received for publication Aug 5, 2020; revisions received Aug 5, 2020; accepted for publication Aug 6, 2020; available ahead of print Aug 15, 2020.

Address for reprints: Richard Lee, MD, MBA, Division of Cardiothoracic Surgery, Department of Surgery, Augusta University, Medical College of Georgia, Augusta, Ga (E-mail: ricklee@augusta.edu).

J Thorac Cardiovasc Surg 2021;162:1106-7

$0022-5223 / \$ 36.00$

Copyright (c) 2020 by The American Association for Thoracic Surgery

https://doi.org/10.1016/j.jtcvs.2020.08.040

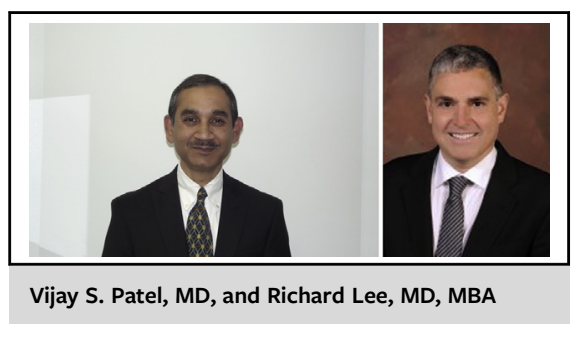

CENTRAL MESSAGE

Surgical ablation of atrial fibrilla-

tion in patients with heart failure:

evidence or anecdote?

resonance imaging to exclude patients unlikely to benefit from an ablation procedure. Regarding their operative approach, the article emphasizes the importance of the CMP-IV procedure, which is technically less challenging and yet associated with comparable outcomes to the classic Cox-maze procedure. ${ }^{6}$ Unfortunately, they provide no details specific to their choice of sternotomy versus right thoracotomy, operative procedure, descriptions of lesions, discussion of alternate energy sources beyond their preferred radiofrequency and cryoablation energy devices, and outcomes with other less invasive SA procedures without biatrial lesions.

A retrospective report from this highly experienced center ( $>15$ years) includes 34 patients primarily with persistent and/or long-standing AF who underwent a standalone CMP-IV procedure. They report 94\% freedom from recurrent atrial tachyarrhythmia at 2 years, improvement of left ventricular ejection fraction and New York Heart Association functional classification, and low complication rate. ${ }^{7}$ These results are comparable to the few similar retrospective reports from other highly experienced centers. ${ }^{8-10}$ Collectively, they represent a small volume of patients, and the authors do not explain the lack of referrals. Despite these favorable outcomes, there is a lack of conclusive large retrospective or prospective randomized multicenter clinical studies. The absence of this data may be due to resistance within the medical and specialty physician community to refer patients for stand-alone SA; knowledge, experience, and adoption of the CMP-IV procedure by the larger surgical community; and the perceived greater risks with no persuasive median or long-term outcomes data.

Whether this is considered evidence or anecdote, the authors must be commended for making a convincing argument and, in their opinion, future Society Guidelines 
should incorporate the concomitant or stand-alone CMP-IV procedure for the management of eligible patients with $\mathrm{AF}$ or HF with or without correctable structural heart disease, respectively. The article provides a valuable clinical framework to potentially serve many more patients with biatrial CMP-IV procedure, and their appeal is worthy of consideration by the Society's Guidelines Committee.

\section{References}

1. Benjamin EJ, Muntner P, Alonso A, Bittencourt MS, Callaway CW, Carson AP, et al. Heart disease and stroke statistics-2019 update: a report from the American Heart Association. Circulation. 2019;139:e56-528.

2. Santhanakrishnan R, Wang N, Larson MG, Magnani JW, McManus DD, Lubitz SA, et al. Atrial fibrillation begets heart failure and vice versa: temporal associations and differences in preserved versus reduced ejection fraction. Circulation. 2016;133:484-92.

3. Khiabani AJ, Schuessler RB, Damiano RJ Jr. Surgical ablation of atrial fibrillation in patients with heart failure. J Thorac Cardiovasc Surg. 2021;162:1100-5.
4. Badhwar V, Rankin JS, Damiano RJ Jr, Gillinov AM, Bakaeen FG, Edgerton JR, et al. The Society of Thoracic Surgeons 2017 clinical practice guidelines for the surgical treatment of atrial fibrillation. Ann Thorac Surg. 2017;103:329-41.

5. Ad N, Damiano RJ Jr, Badhwar V, Calkins H, La Meir M, Nitta T, et al. Expert consensus guidelines: examining surgical ablation for atrial fibrillation. J Thorac Cardiovasc Surg. 2017;153:1330-13354.e1.

6. Ruaengsri C, Schill MR, Khiabani AJ, Schuessler RB, Melby SJ, Damiano RJ Jr. The Cox-maze IV procedure in its second decade: still the gold standard? Eur J Cardiothorac Surg. 2018;53(suppl 1):119-25.

7. Adademir T, Khiabani AJ, Schill MR, Moon MR, Melby SJ, Damiano RJ Jr. Surgical ablation of atrial fibrillation in patients with tachycardia-induced cardiomyopathy. Ann Thorac Surg. 2019;108:443-50.

8. Stulak JM, Dearani JA, Daly RC, Zehr KJ, Sundt TM III, Schaff HV. Left ventricular dysfunction in atrial fibrillation: restoration of sinus rhythm by the Cox-maze procedure significantly improves systolic function and functional status. Ann Thorac Surg. 2006;82:494-501.

9. Ad N, Henry L, Hunt S. The impact of surgical ablation in patients with low ejection fraction, heart failure, and atrial fibrillation. Eur J Cardiothorac Surg. 2011; 40:70-6.

10. Pozzoli A, Taramasso M, Coppola G, Kamami M, La Canna G, Della Bella P, et al. Maze surgery normalizes left ventricular function in patients with persistent lone atrial fibrillation. Eur J Cardiothorac Surg. 2014;46:871-6.
See Article page 1100.

\section{Commentary: "Chicken or the egg": The causality dilemma of atrial fibrillation and congestive heart failure}

\author{
Gabor Bagameri, MD, and John M. Stulak, MD
}

In their article in this issue of the Journal, Khiabani and colleagues ${ }^{1}$ advocate surgical ablation of atrial fibrillation $(\mathrm{AF})$ in patients with heart failure (HF). AF and HF can coexist, which can lead to a vicious cycle, with both being a potential cause and/or consequence. This association between $\mathrm{AF}$ and $\mathrm{HF}$ was appreciated long ago and raises

From the Department of Cardiovascular Surgery, Mayo Clinic College of Medicine and Science, Rochester, Minn.

Disclosures: The authors reported no conflicts of interest.

The Journal policy requires editors and reviewers to disclose conflicts of interest and to decline handling or reviewing manuscripts for which they may have a conflict of interest. The editors and reviewers of this article have no conflicts of interest.

Received for publication June 27, 2020; revisions received June 27, 2020; accepted for publication June 29, 2020; available ahead of print July 11, 2020.

Address for reprints: John M. Stulak, MD, Department of Cardiovascular Surgery, Mayo Clinic College of Medicine and Science, 200 First St SW, Rochester, MN 55905 (E-mail: stulak.john@ mayo.edu).

J Thorac Cardiovasc Surg 2021;162:1107-8 0022-5223/\$36.00

Copyright $(5) 2020$ Published by Elsevier Inc. on behalf of The American Association for Thoracic Surgery

https://doi.org/10.1016/j.jtcvs.2020.06.094

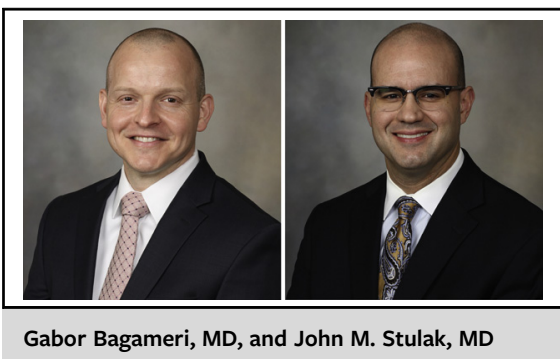

CENTRAL MESSAGE

The success and clinical impact of stand-alone or concomitant surgical ablation of atrial fibrillation (AF) in the presence of heart failure are directly related to whether AF is a cause of or the result of heart failure.

the question of "atrial fibrillation or heart failure?" in a way similar to that in the folk paradox of the "chicken or the egg" first proposed by ancient Greek philosophers to describe the problem of determining cause and effect. However, unlike with the chicken and the egg, determining causality in the case of AF in HF is critical for success.

The pathophysiological relationship between $\mathrm{AF}$ and $\mathrm{HF}$ is complex and variable and while it has been extensively 